Bagashvili Zurab

Grigol Robakidze University, Georgia

\title{
Transition from passive to active vocabulary in the context of teaching by communicative methods
}

\begin{abstract}
In the learning process of any foreign language the most important factor is to learn the vocabulary of the language. Learners first form the passive knowledge of the lexis and after this they put it into practice through communicative speech functions. In order to make any passive vocabulary active, stable and fast, communicative teaching methodology is based on speaking skills, developing knowledge realization process. This problem is connected with attaining the second foreign language intensively. Besides methodological attitudes, opinions differ about defining a daily amount of vocabulary to be leant by language learners:

1. The first issue is how many new words should be appropriate to be learned in the case of 1 or 2 days of intervals.

2. To determine whether there is a methodological necessity to strictly define the amount of new words, taking into account context and phrasal expressions.

Considering language level competences (A1 C 2) we should determine the most used language environment (bank, public service hall....), appropriate amount of vocabulary and divide it into a monthly, semester or annual index. We should also take into account the time set for learning and objectives of the curriculum: what time is allotted to language learners to fulfill their aims: a) crash course for language learners; b) ordinary course unfolding during the semester. For the first case the amount of words to learn can be 20 - 25 to be given every other day over 16 weeks. In other words this can be distributed over 4 months. As for the second case, students should be given $10-12$ words each day and this course will last 8 months. In order to make this vocabulary active swiftly, the amount of new words and lesson material should be appropriate to the learner's competences. The most important here should be oral practice and communicative approaches, dialogues and simulation situations. Very effective would be using the Callan Method, that is focused on learning language grammar and vocabulary to the B2 level. The objective of this work is a discussion of the formation of the active vocabulary process in the aspect of communicative methodology and working out recommendations for its methodological improvement as given below: a) Defining the most frequently used Georgian vocabulary according to the different levels, as well as the amount of new words and the content from lesson to lesson. b) Taking into account lexicological principles in creating textbooks for Georgian Language Learners and defining the amount of university (school) curriculum hours. c) Working out methodologically the possibility of putting into practice teaching Georgian similarly employing the Callan Method and its scientific principles. Conducting practical experiments and, if the results are efficient, considering it to be preferable.
\end{abstract}

Key words: Second language education; vocabulary of the language; Callan Method.

In the learning process of any foreign language the most important factor is to learn the vocabulary of the language. Learners first form the passive knowledge of the lexis and after this they put it into practice through communicative speech functions. In order to make any passive vocabulary active, stable and fast, communicative teaching methodology is based on speaking skills and a developing knowledge realization process. This problem is connected with attaining the second foreign language intensively. Besides 
methodological attitudes, opinions differ about defining a daily amount of vocabulary to be leant by language learners:

1. The first issue is how many new words should be appropriate to be learned in the case of 1 or 2 days of intervals.

2. To determine whether there is a methodological necessity to strictly define the amount of new words, taking into account context and phrasal expressions.

In my article I use quantitative and observational methods during 18 years of uninterrupted teaching of Georgian as a second language, I have had an opportunity to observe different linguistic and age groups and to come to the conclusions discussed below.

One methodology has an influence over another. Communicative methods were worked out by teachers and linguists who were dissatisfied with the results of audio linguistic, grammatical and translating teaching methods. They werez convinced that students weren't able to adopt language as properly as they should have. The students were unable to communicate using the necessary social language, expressions and gestures. Consequently they were confused about how to use a language in the native cultural environment of the language. The interest and development of communicative language teaching methodology emerged in the $70 \mathrm{~s}$ of the last century. Using the adopted language and conversation in classes, when students were involved in the real communication with one another became very critical.

In the communicative language teaching process teachers use real situations, that creates the need for communication. A teacher creates a situation that makes the students imagine real life events. Different from the audio linguistic method, that is based on the repetitions, this communicative method encourages students to wait for real results, the results of the exercise that they do in class, and depends on their activity and involvements in the process. Simulation situations vary from day to day. The motivation of studying the language depends on the students will to communicate about common everyday situations. According to Merge any language represents an interaction, it's the verbal communication between individuals and is closely related to the society. From his point of view in the language learning process the most important is using the language according to the real context (we mean what is mentioned previously and after the statement), and according to the social and situational context (who is speaking, what social status they have, why did they gather together to speak about it etc.) (Merge, 1991).

Students generally communicate with their own language structures. For instance, a non-native Georgian speaker, who learns Georgian, creates phrases with errors. It's the result of thinking in the native language to make the sentence in Georgian. The vocabulary and the grammar of their language are deeply contrasted from of the language they learn. In that case students create so called "inter-language system" and try to learn the language according to it.

Grammatical method that helps to make correct grammatical constructions is a part of developing "interlanguage system", but it is not as perfect as in the case of adopting grammatical rules incorrectly, the statement construction made by the student is wrong anyway. The audio method is not as perfect either as the student might not be able to acknowledge the habit or the manner of speaking or still make mistakes.

The method that was perfect in this area is the communicative method. This method is used together with grammatical and audio linguistic methods, as the method supports the student to create a correct inter languages system and speak correctly and fluently in the new language. The teacher makes efforts in order not to speak themselves, but to force the students to practice speaking as much as possible.

It's essential for language teaching not to make it monotonous and intermediately oriented. Language constructions can be created in advance but they can be made spontaneously as well. Language is never static. Lessons should be improvised, without previous preparation, and natural. Spontaneous and improvised exercises help listeners to develop memory. Alternative means are very important as well, such as changing the subject of the conversation and so on. Discussing newspapers, magazines, some verses, new programs, telephone directories, videos, films, current affair news etc. is also very fruitful. 
E ISSN 1512-3146 (online) ISSN 1987-9601 (print)
International Journal

of Multilingual Education

The communication method doesn't exclude learning dialectical terms or slang in the learning process. In this case the most important is learning issues defined in the syllabus and not the whole textbook. The textbook might be used as additional material. The teacher should define themselves which exercises, points or phrases should be practiced.

There exist various views about remembering new words. Shtal recommends the teachers to use the "context and definition" strategy in teaching new vocabulary, as well as synonyms, antonyms, affixes, the roots of words, classifications and others. (Shtal, 1986)

Baumann, J.F., \& Kameenui, E.J. define three levels of the word learning process, that clarify the depth of understanding of a word and help the teacher to select the proper method. Thee three levels are known as associational level, understanding level and using level. A student, who has competences in the associational level, can connect a new word to certain definitions or context. As for the second level the student hears the new word, can name a synonym, antonym and define the word's grammatical category. The last using level of the word enables the student to select a new context for the new word (e.g. enables them to make a new sentence using a new word) or give the definition of the new word using the vocabulary they already know. (Baumann, J.F. \& Kameenui, E.J. 1991, p. 201).

There are many methodologists working on the issues today. According to John Dowly upgrading the new vocabulary depends on the understanding of the word's definition and its meaning in a certain sentence.

John Harmony (1991) describes 8 means that are most often used in teaching new vocabulary. These means are as follows:

synonyms; short description; examples; no examples; periphrasis; repletion; association; using special words (meaning contexts or different context).

Defining the amount of new vocabulary in the Georgian language should be based on a different principle from European languages.

Remembering nouns or other parts of speech is easy compared to the verb itself. Although there must be defined several psycholinguistic factors that are especially important when learning Georgian as a foreign language.

a) Concentrating on the associational meaning of the word and remembering by this mean (we mean what the word remembers for you, like onomatopoeia).

b) How popular the word is and how frequently it is in use. Frequently used words are more important to learn than those that are rarely used.

c) The efficiency of remembering vocabulary depends on how close it is to the age and consciousness of the learner. Accordingly, a child or a youth can remember words better if they are interesting in them rather than those that are not familiar for their world.

As Georgian is an agglutinative language and not inflexible or fundamental, the amount of the new vocabulary given to learn by heart should be different. And using English in this way as an example language would be inadvisable.

During my long teaching experience I found out that at language learning centers, schools or high schools teachers don't focus on the gradual increase of the amount of new words that are given to students for learning. They work according to the basic principle and force their students to learn all the new vocabulary that is given in the new material.

Generally, it seems logical, but a student might already know some of the words and it will hinder the process of vocabulary learning... everyone knows there are 500 English words, knowledge of which enables you to attain basic communicative language (A1 - A2 levels) ... The kinds of these models would be appropriate for Georgian teachers and textbook authors to work out appropriate methods of teaching, wouldn't they? 
It's worth mentioning that the textbooks that we already have for Georgian language learning include upgrading new vocabulary on a daily basis, but they mainly concentrate on the thematic principle and functional grammar. At the time when these textbooks were written, teaching Georgian as a foreign language was a new subject and due to the agglutinative nature of the language, authors couldn't consider the proper amount of new vocabulary to be given to the students, with respect to the English or Russian languages.

Principle difficulties for foreigners are as follows:

Agglutinative language is formed by affixes;

The Georgian verb is polyvalent;

The Georgian language is rich with affixes: forms that help to form words;

A Georgian verb has 11 screeves, 4 voices a complex system of participles... root changing verbs according to number and person.;

system of the screeves of the Georgian verb makes it difficult to learn the verb and the sentence generally; cases - ergative case is the case of the subject.

English language learners study10 lexicological units from lesson to lesson. The word "love" is among them. They already know at the time what are the personal pronouns such as I, you, he etc. .. and it's not difficult for them to understand and learn how to use these words in sentences: I love you, You love me, He

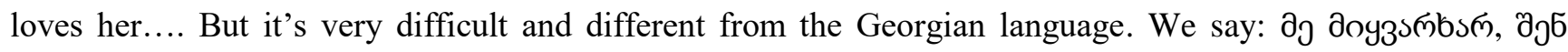

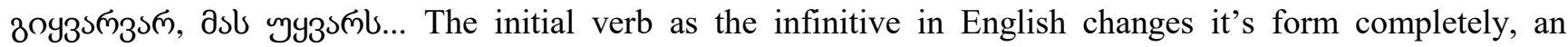
auxiliary verb is added, that is not known to the language learners. Let's compare due to the sound amounts: boyzsmymo - doyzsmbsm, the root has changed, the common part here is "ogзsmym ", that is absolutely confusing for the learners. If we put the verb in the past indicative, we get the word " $y 3$ ১๓ part that remains the same and the changes are very confusing.

We have to define the most used social environment according to language competences (A1-C2) (bank, public service hall...), the appropriate amount of lexicological units and divide this number by monthly, semester or annual units. We have to take into account the time budget for learning and curricular goals : what is the time determined for the language learners to study the language, these are: a) fast course of learning the language and 2) "ordinary" course determined in the academic semester.

If we take the first course the amount of new words that the students should study is 20-25 words every other day for 16 weeks (4 months in the long run). As for the second course (ordinary) the amount of words should be about 10-12 from lesson to lesson and the duration of the course should be 8 months. To put all this vocabulary into practice, from passive into active, as quickly as possible, the theme and the amount of new vocabulary should be defined according to the level of the language learners. Communicative attitudes and speaking practice should be the highest priority in the learning process and dialogues and simulation situations should be used... Very effective would be using the method similar to the Callan Method, that is focused on learning language grammar and vocabulary to the $\mathrm{C} 2$ level.

What are the main characteristics of the method?

Teaching by the Callan method gets the students deeply involved in the learning process. This is a structurally strong and efficient program that is divided into 12 stages. The listeners are in the center of the process. The students are given opportunity to speak the language as much as possible. A teacher asks a lot of questions, that stimulates students' attention. This method maintains gradual progress in grammar and vocabulary learning.

This method involves asking and answering questions at high speed. The teacher asks a question and the student answers the question with the teacher, but the teacher always precedes the student for less than a second time. This method develops thinking directly in English without translation from the native language and also speaking reflexively in the language. 
High speed of the lesson, constant repetition of the vocabulary and fast questions develop the students' minds, stimulation of the students' memory, keeping the received knowledge in the mind for good that helps students to speak English fluently.

The method of correcting mistakes is also different. The mistake made by a student is corrected immediately, that excludes remembering wrong pronunciation of words.

The Callan method teaches students not to answer the question, but to make the sentence, controlling proper vocabulary and sentence structures. It's the direct method of teaching the language, which involves avoiding translations as much as possible. As for the communicative means the method uses miming and gestures. A lot of time is dedicated to repetition, not only of certain lessons but even of the whole stages. (Describing the Callan method we use the definition of the method by the British Center, 2013)

Consequently, the aim of the method is accuracy, speed, flexible thinking directly in the foreign language. Practicing this method, in my view efficiently deals the main issue in the article: putting the passive vocabulary into live speaking practice... it's the most important issue because language learners can only speak the new language using active vocabulary, not passive...

Accordingly for the development of the active vocabulary and its effectiveness, it's advisable:

a) to determine the amount of those mostly used Georgian words according to the level and define the amount of the vocabulary and content of these words from lesson to lesson;

b) creating Georgian language textbooks for foreigners, the authors should take into account "lexicological principles" and define university (school) curriculum amount of hours;

c) working out methodologically the possibility of putting into practice teaching Georgian similar to the Callan Method and its scientific principles. Conducting practical experiment and if the results are efficient, considering it as preferable. 


\section{References}

Bagashvili, 2006 - Methodology of teaching a foreign language. Zurab Bagashvili, Tbilisi, (2006).

Bagashvili, Marika Odzeli, 2006 - Development of Communicative competences, Zurab Bagashvili, Marika Odzeli, Tbilisi, (2006).

Baumann, Kameenui, 1991 - Baumann, J.F. \& Kameenui, E.J. (1991). Research on vocabulary instruction:

Flood and others, 1993 - Ode to Voltaire. In J. Flood, J. M. Jensen, D. Lapp \& J. R. Squire (Eds.), Handbook of research on teaching the English language arts (pp. 604 - 632). New York: Macmillan.

Harmon, 1998 - Harmon, J. G. (1998). Vocabulary teaching and learning in a seventh-grade literature-based classroom. Journal of Adolescent \& Adult Literacy, 41, 518 - 520.

Peremena, 2002 - Реремена, (2002). Vilnius, 1.

http://www.britishcentre.ge 